\title{
Treatment with Myf5-morpholino results in somite patterning and brain formation defects in zebrafish
}

\begin{abstract}
Myf-5 is a stage-dependent transcription factor associated with somitogenesis. To study its biological functions in zebrafish, we injected the Myf5-morpholinos ZMF-MO (antisense nucleotides 28 to 52) and ZMF-OTHER (antisense nucleotides 3 to 27) into zebrafish embryos to establish a myf-5 gene knockdown. No phenotypic abnormalities were observed following injection with $0.2 \mathrm{ng}$ of ZMF-MO, but defects were displayed in 2 of $118(1.7 \%)$ surviving embryos injected with $1 \mathrm{ng}$ ZMF-MO. Morphological defects became more severe with increased dosages: 105 of 270 (38.9\%) surviving embryos injected with $4.5 \mathrm{ng}$ of ZMF-MO displayed such abnormalities as the absence of eyes or brains in addition to the following low-dosage defects in 24 hpf embryos: longitudinal yolk sacs, incomplete epiboly coverage, abnormal and suspended tail buds, diffused somite boundaries, and head shrinkage. Similar results were observed in the $4.5 \mathrm{ng}$ ZMF-OTHER injection group. However, when fish were co-injected with 4.5 ng ZMF-MO and $4.5 \mathrm{ng} m y f-5$ mRNA, abnormality rates decreased from $49.6 \%$ to $5.5 \%$. Our results show that the brain krox20 gene was down-regulated at rhombomere 3; the pax2.1 gene was completely down-regulated; myo D was expressed normally; myogenin was substantially down-regulated in whole somites; and desmin was partly inhibited in newly forming somites. Our conclusion is that zebrafish Myf-5 may play important roles in brain formation and in the convergence and extension of shield epiblasts and tail buds during early embryogenesis, in addition to its well-understood role as a muscle regulatory factor in somites.
\end{abstract}

Y.-H. Chen · H.-J. Tsai (

Institute of Fisheries Science, National Taiwan University,

1 Roosevelt Road, Sec. 4, Taipei, Taiwan

Tel: +88622366 1540, Fax: +886223638483

e-mail: hjtsai@ccms.ntu.edu.tw
Key words brain $\cdot$ embryogenesis $\cdot$ fish $\cdot$ morphant . morpholino $\cdot m y f-5 \cdot$ somite

\section{Introduction}

In eukaryotic cells, muscle-specific gene transcription is controlled by a series of complex interactions among DNA-binding transcription factors and specific DNA recognition sequences. These factors can be categorized in terms of shared sequences and structural motifs, including the basic helix-loop-helix (bHLH) motif. Myogenesis involves several bHLH proteins, such as MyoD, MYF-5, Myogenin, and MRF4. The moleculars of myogenic regulatory factors (MRFs) have been identified in mammals (Buonanno et al., 1992), birds (Saitoh et al., 1993), frogs (Hopwood et al., 1991), fish (Chen et al., 2000; 2002), insects (Michelson et al., 1990) and nematodes (Krause et al., 1994).

In mice, MyoD and Myf-5 play distinct roles in myogenesis. Cells in the epaxial myotome usually express $m y o \mathrm{D}$, while hypaxial myotomes express $m y f-5$ (Rudnicki and Jaenisch, 1995). Epaxial and hypaxial myotomes eventually differentiate into limbs and trunk muscles, respectively. Braun et al. (1992) reported that the targeted inactivation of $m y f-5$ results in embryonic death; the mice embryos they studied were unable to breathe owing to the absence of ribs and sternum, even though normal muscle development was observed. In fish, the biological functions of Myf-5 have yet to be fully characterized. One exception is Neyt et al.'s (2000) use of zebrafish myo D as a molecular marker to demonstrate that teleost fin muscles in tetrapod species develop from migratory mesenchymal precursor cells that possess molecular and morphogenetic similarities with limb muscle precursors. However, no reports have been published to date on the targeted inactivation or gene knockdown of fish myf-5. 
Recently, Chen et al. (2001) and Coutelle et al. (2001) reported that zebrafish $m y f-5$ transcripts were detectable at 7.5 hours post-fertilization (hpf), increased substantially until $16 \mathrm{hpf}$, then gradually declined to undetectable levels by $26 \mathrm{hpf}$. They also found that during somitogenesis, zebrafish myf-5 transcripts were primarily found in somites and segmental plates. Prominent signals occurred transiently in adaxial cells in two parallel rows, but did not extend beyond positive-signal somites. Since adaxial cells and presomitic mesoderms are precursors of slow and fast muscles, respectively (Devoto et al., 1996), we believe that zebrafish $m y f-5$ may be involved in slow and fast muscle formation.

Morpholino, a nucleotide analogue, has been described by Nasevicus and Ekker (2000) as a powerful tool for gene function knockdown in zebrafish. To determine the biological functions of zebrafish $m y f-5$, we injected Myf5-morpholino (myf5-MO) into single-cell zebrafish embryos and recorded the resulting $m y f-5$ knockdown phenotypes. From our observations of zebrafish $m y f-5$ morphants, we found that $m y f-5$ is not only involved in myogenesis, but also plays important roles during early embryogenesis in the convergence and extension of shield epiblasts, as well as in tail bud and brain formation.

\section{Methods}

Fish

AB strain Zebrafish were kept at a photoperiod of $14 \mathrm{~h}$ light/10 h dark at approximately $28.5^{\circ} \mathrm{C}$. After fertilization, eggs were collected and cultured in an aquarium. Embryonic cleavage numbers were counted and somite formation observed with a light microscope to determine developmental stage (Kimmel et al., 1995).

Preparation and microinjection of morpholino

Zebrafish myf5-morpholino (ZMF-MO: 5'-TACGTCCATGATTGGTTTGGTGTTG-3') and myf5-morpholino-other (ZMFOTHER: 5'-AAGGTTTCTGAGTGGTGTGGTTGCA-3') were established based on zebrafish myf-5 cDNA complementary sequences from nucleotides (nt) 28 to 52 and 3 to 27 , respectively (Gene Tools). Fluoresceinated chordin-MO (5'-ATCCACAGCAGCCCTCCATCATCC-3') and standard control (nonspecific) MO (STD-MO) (5'-CCTCTTACCTCAGTTACAATTTATA-3') were used as positive and negative controls, respectively (Gene Tools). All of the above were prepared at stocking concentrations of $1 \mathrm{mM}$ and diluted with double-distilled water to concentrations of $10,53,133$ and $250 \mu \mathrm{M}$ (4.5 ng/embryo).

For our rescue experiment, we established the primers ZMFC1F (5'-CCCAGTGCAACCACACCAC-3') and ZMFC1433R (5'-CCCGTTATTAAATAACACATTT-3') to amplify full-length zebrafish $m y f-5$ cDNA by reverse transcription-polymerase chain reaction, using Superscript II (Gibco) and ExTaq DNA polymerase (TAKARA) as described in Chen et al. (2001). The resulting PCR product was ligated to pGEMT-easy vector (Promega); the $m y f-5$ cDNA in pT7-ZMF was driven by the T7 promoter. To construct pT7-EGFP, in which EGFP cDNA was also driven by the T7 promoter, primers GFP-F (5'-ATGGTGAGCAAGGGCGAGGA-3') and GFP-R (5'-CAGCTCGTCCATGCCATGTG-3') were syn- thesized and processed for PCR. For $m y f-5$ or GFP mRNA preparation, approximately $5 \mu \mathrm{g}$ of SpeI-digested pT7-ZMF or pT7EGFP and mMESSAGE mMACHINETM (Ambion) were manufactured according to the supplier's directions. After synthesis, $m y f$ 5 and GFP mRNAs were diluted to working concentrations of 100 , 500,750 and $2000 \mathrm{ng} / \mu \mathrm{l}$ prior to each $2.3 \mathrm{nl}$ injection.

\section{Digoxigenin (DIG)-labeled riboprobe preparation}

Approximately $5 \mu \mathrm{g}$ each of plasmids containing cDNA of desmin (nt 1 to 1772) (Loh et al., 2000; Xu et al., 2000), myoD (nt 216 to 951) (Weinberg et al., 1996), myogenin (nt 114 to 833) (Chen et al., 2000), pax2.1 (nt 1214 to 1854) (Pfeffer et al., 1998), and krox20 (nt 463 to 1021) (Oxtoby and Jowett, 1993) - all driven by a T7 promoter - were used as templates to prepare riboprobes (DIG RNA Labeling Kit, Rosche).

\section{Whole-mount in situ hybridization}

Normal and morphant embryos were collected at $24 \mathrm{hpf}$, fixed with $4 \%$ paraformaldehyde for $4 \mathrm{~h}$ at $25^{\circ} \mathrm{C}$, dechrionized, dehydrated with an ascending methanol series $(25 \%, 50 \%, 75 \%$ and $100 \%)$, and stored in methanol at $-20{ }^{\circ} \mathrm{C}$. The in situ hybridization of whole embryos was performed using DIG-labeled riboprobes of desmin, myoD, myogenin, pax 2.1, and krox 20 according to procedures described in Chen et al. (2001), with some modifications. Embryos were permeabilized with acetone at $-20^{\circ} \mathrm{C}$, digested with $10 \mu \mathrm{g} / \mathrm{ml}$ proteinase $\mathrm{K}$ for $15 \mathrm{~min}$, and prehybridized for at least 4 h. Hybridization took place at $70^{\circ} \mathrm{C}$ in the presence of approximately $10 \mathrm{ng}$ DIG-labeled riboprobes for a minimum of $16 \mathrm{~h}$. After washing, hybridized embryos were incubated overnight in a 1:10,000 dilution of alkaline phosphatase-conjugated anti-DIG antibody (Rosche) at $4{ }^{\circ} \mathrm{C}$. Excess antibodies were removed by progressively longer washings with $0.1 \%$ Tween-20 in phosphate-buffered saline $(10,10,10,20,30$, and $60 \mathrm{~min})$. Color reactions (using nitroblue tetrazolium and 5-bromo-4-chloro-3-indolyl phosphate as substrates) were used to detect the hybridized myoD, desmin, myogenin, pax 2.1 , and krox $20 \mathrm{mRNA}$ transcripts.

\section{Embedding and cryosectioning}

Morphants and wild-type embryos were fixed with $4 \%$ paraformaldehyde for $4 \mathrm{~h}$ at $25^{\circ} \mathrm{C}$, dechrionized, mounted with $5 \%$ sucrose containing $1.5 \%$ agarose for $1 \mathrm{~h}$, cut into cubes approximately $5 \times$ $5 \times 5 \mathrm{~mm}$ and stored in $5 \%$ sucrose at $4{ }^{\circ} \mathrm{C}$. All embryos were embedded using Cryomatrix (Shandon); cryosectioning (15 $\mu \mathrm{m}$ thick) was performed with a Microm Cryosector (Heidelberg).

\section{Microscopy}

All wide-type, morphant, and stained embryos were examined with a DMR microscope and photographed with a MPS 60 camera (both from Leica) using FUJI X-TRA 400 ASA film.

\section{Results}

\section{Defective morphology in Myf5-MO-injected embryos}

First, we injected a chordin antisense morpholino (chordin-MO) conjugated with fluorescein into zebrafish embryos as a positive control to observe specific phenotypes. Embryos injected with $4.5 \mathrm{ng}$ of chordin-MO resulted in phenotypes marked by small heads, extremely 


\section{Chordin-Morphants}

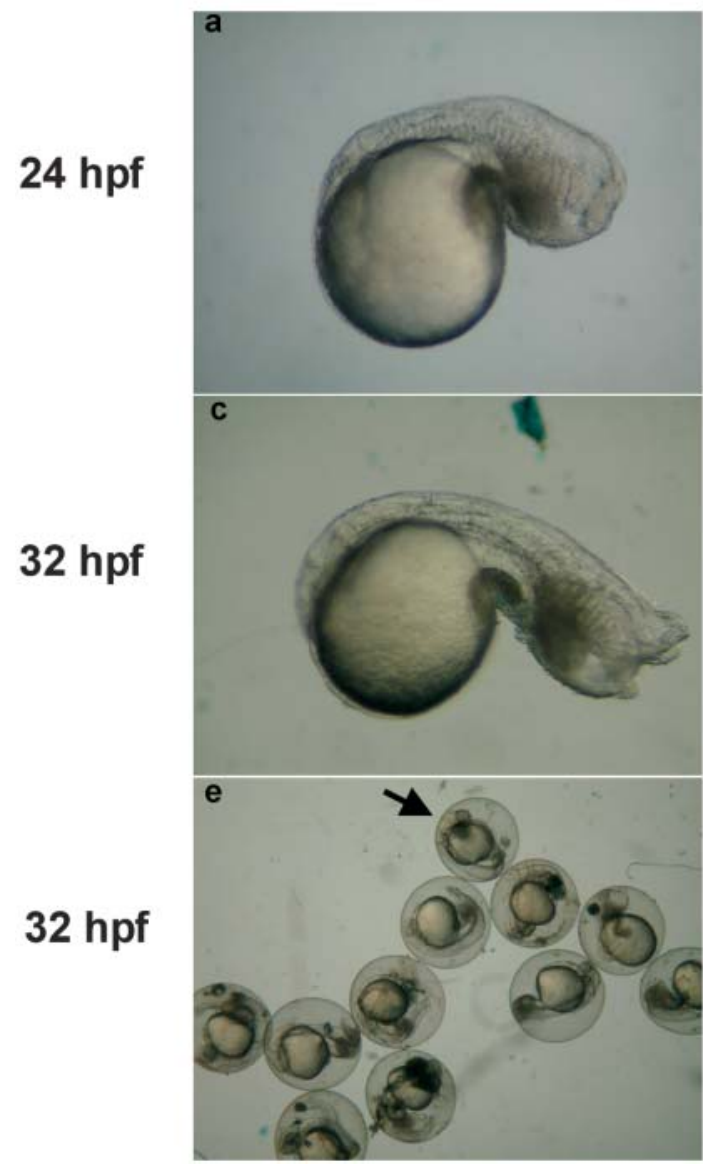

Fig. 1 Observation of chordin-morphants. Chordin-morphants developed at $24(\mathbf{a}, \mathbf{b})$ and $32 \mathrm{hpf}(\mathbf{c}-\mathbf{f})$ were observed and photographed under bright field illumination (a, $\mathbf{c}$ and $\mathbf{e}$ ) and blue light (b, d and f). Wild-type embryos developed at 24 (g) and $32 \mathrm{hpf}(\mathbf{h})$

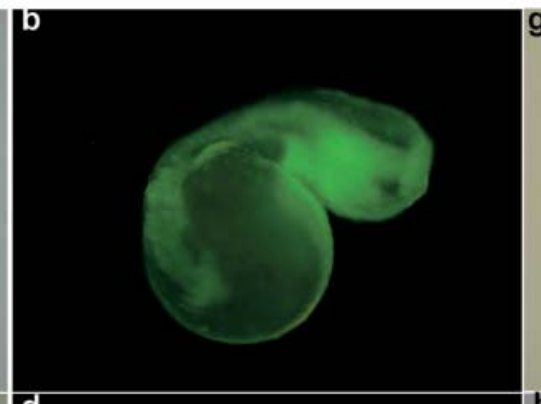

\section{Wild-type}
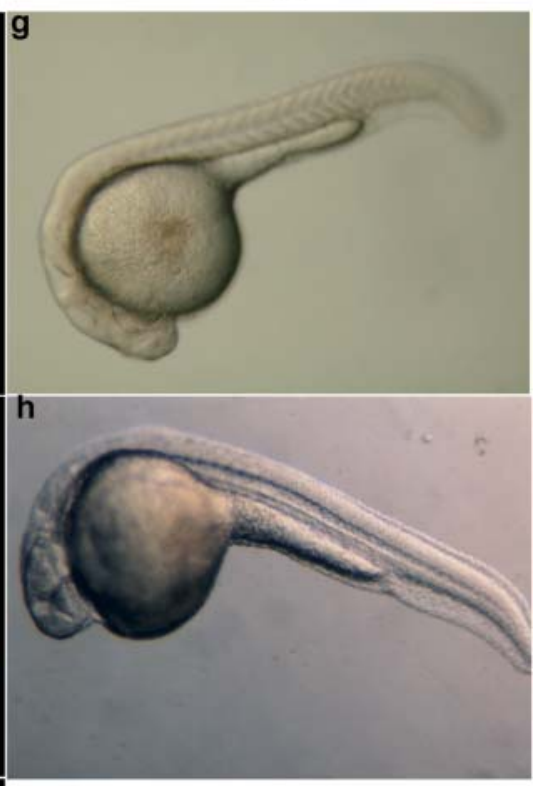

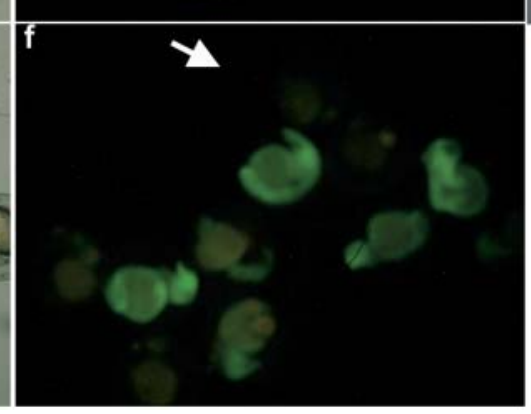

were also illustrated. Arrows indicate that no green signals were detected in chordin-MO-injection group (f), resulting in normal phenotype (e).

No abnormal phenotypes were observed in negative control embryos injected with standard control/non-specific MO (STD-MO); survival was measured at $87.3 \%$ (Table 1). Likewise, no abnormal phenotypes were observed in mock control embryos injected with the same volume of double-distilled water, with an $86.5 \%$ survival rate (Table 1). In the experimental group, all 150 sur-

Table 1 Dose response of phenotypes caused by ZMF-MO and ZMF-OTHER injection

\begin{tabular}{|c|c|c|c|c|c|c|c|c|}
\hline \multirow{2}{*}{$\begin{array}{l}\text { Injection dose } \\
\text { (ng/embryo) }\end{array}$} & \multirow[t]{2}{*}{ Mock } & \multicolumn{4}{|l|}{ ZMF-MO } & \multirow{2}{*}{$\frac{\text { ZMF-OTHER }}{4.5}$} & \multirow{2}{*}{$\frac{\text { STD-MO }}{4.5}$} & \multirow{2}{*}{$\frac{\text { Chordin-MO }}{4.5}$} \\
\hline & & 0.2 & 1 & 2.5 & 4.5 & & & \\
\hline Injection embryos & 334 & 178 & 193 & 142 & 501 & 466 & 166 & 193 \\
\hline Survival Embryos & $289(86.5 \%)$ & $150(84.3 \%)$ & $118(61.1 \%)$ & $96(67.6 \%)$ & $270(53.9 \%)$ & $266(57.1 \%)$ & $145(87.3 \%)$ & $146(75.6 \%)$ \\
\hline Mild defects & 0 & 0 & $2(1.7 \%)$ & $3(3.1 \%)$ & $42(15.6 \%)$ & $38(14.3 \%)$ & 0 & N.D. \\
\hline Severe defects & 0 & 0 & $9(7.6 \%)$ & $11(11.5 \%)$ & $105(38.9 \%)$ & $86(32.3 \%)$ & 0 & $97(66.4 \%)^{\#}$ \\
\hline
\end{tabular}

The percentages of abnormal phenotypes shown in parentheses were calculated from survival embryos.

\# Severe defects in chordin-MO injection group including reduced head, extremely expanded blood island, abnormal tail fin and Ushaped somites. 


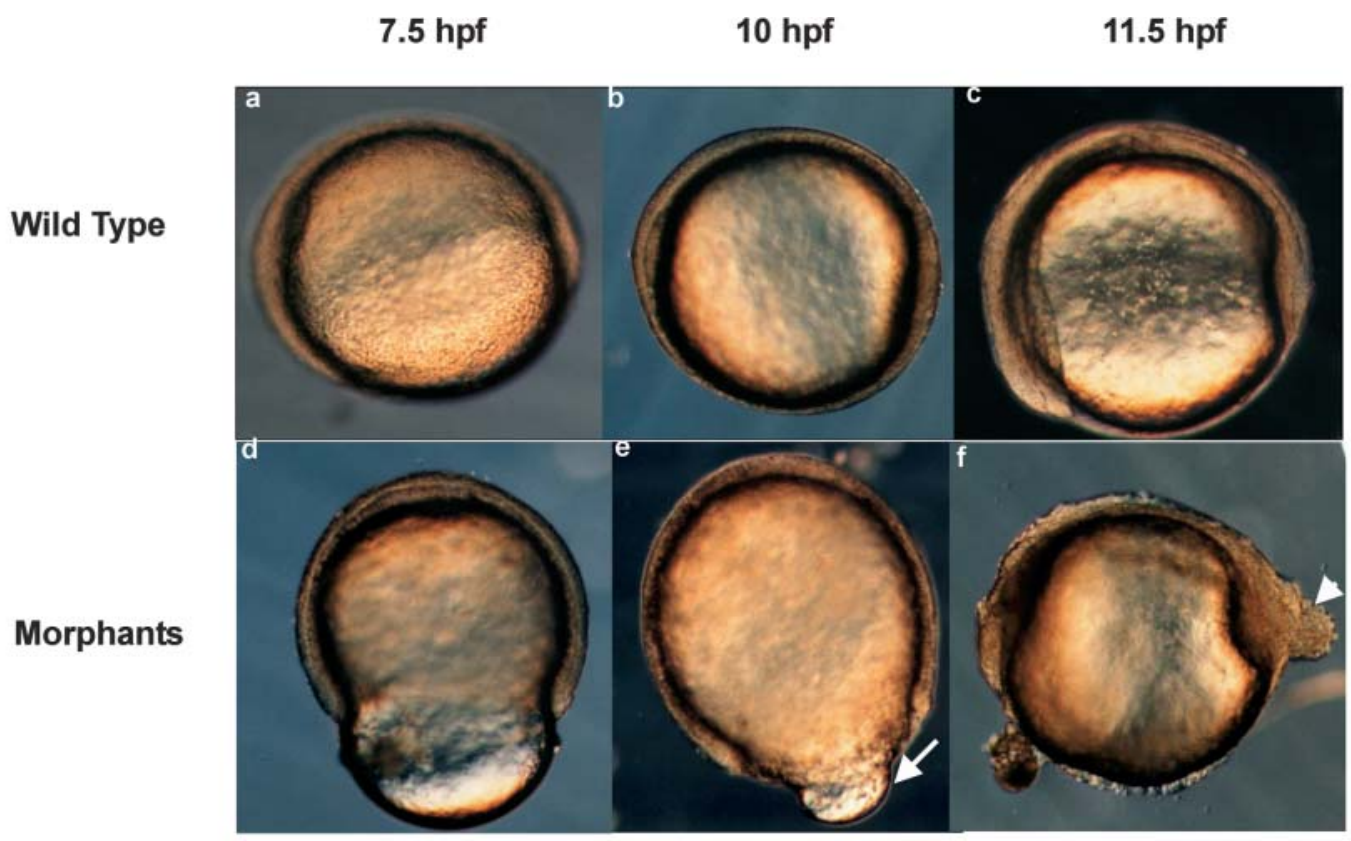

$24 \mathrm{hpf}$

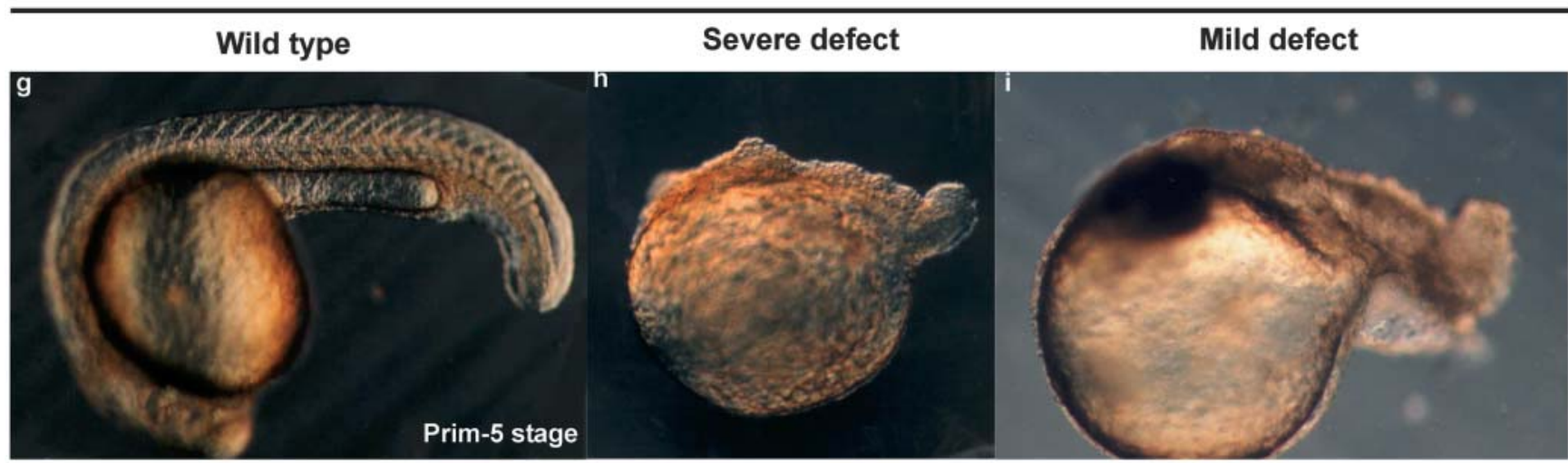

Fig. 2 Dynamic observation of ZMF-morphants. Wild-type embryos $(\mathbf{a}-\mathbf{c}, \mathbf{g})$ and ZMF-morphants $(\mathbf{d}-\mathbf{f}, \mathbf{h}-\mathbf{i})$ developed at 7.5 (a, d), $10(\mathbf{b}, \mathbf{e}), 11.5(\mathbf{c}, \mathbf{f})$ and $24 \mathrm{hpf}(\mathbf{g}-\mathbf{i})$ were observed with a DMR microscope. Arrow and arrowhead indicate incomplete epiboly

viving embryos injected with 0.2 ng myf5-MO displayed normal embryonic development, but those injected with $1,2.5$ or 4.5 ng displayed abnormal phenotypes. coverage and suspended tail bud, respectively. Morphants were classified into severe and mild defects based on morphological abnormalities described in Methods.

At $70 \%$ epiboly (approximately $7.5 \mathrm{hpf}$ ), wide-type embryos displayed spherical shapes (Fig. 2a), while morphants displayed longitudinal shapes and swelling yolk

Table 2 Dose response of phenotypes rescued by coinjection of ZMF-MO and capped zebrafish $m y f-5$ or GFP RNAs

\begin{tabular}{|c|c|c|c|c|c|c|c|}
\hline \multirow[t]{3}{*}{ Injection dose (ng/embryo) } & \multirow[t]{3}{*}{ Mock } & \multicolumn{6}{|c|}{ ZMF-MO (4.5 ng/embryo) } \\
\hline & & \multicolumn{5}{|c|}{ Zebrafish $m y f-5$ RNA } & \multirow{2}{*}{$\frac{\text { GFP RNA }}{4.5}$} \\
\hline & & 0 & 0.23 & 1.15 & 1.725 & 4.5 & \\
\hline Injection embryos & 216 & 404 & 154 & 377 & 287 & 255 & 306 \\
\hline Survival embryos & $193(89.4 \%)$ & $234(57.9 \%)$ & $79(51.3 \%)$ & $177(46.9 \%)$ & $118(41.1 \%)$ & $110(43.1 \%)$ & $180(58.8 \%)$ \\
\hline Mild defects & 0 & $37(15.8 \%)$ & $10(12.7 \%)$ & $16(9 \%)$ & $3(2.5 \%)$ & $6(5.5 \%)$ & $29(16.1 \%)$ \\
\hline Severe defects & 0 & $79(33.8 \%)$ & $23(29.1 \%)$ & $34(19.2 \%)$ & $9(7.6 \%)$ & 0 & $63(35 \%)$ \\
\hline
\end{tabular}

The percentages of abnormal phenotypes shown in parentheses were calculated from survival embryos. 

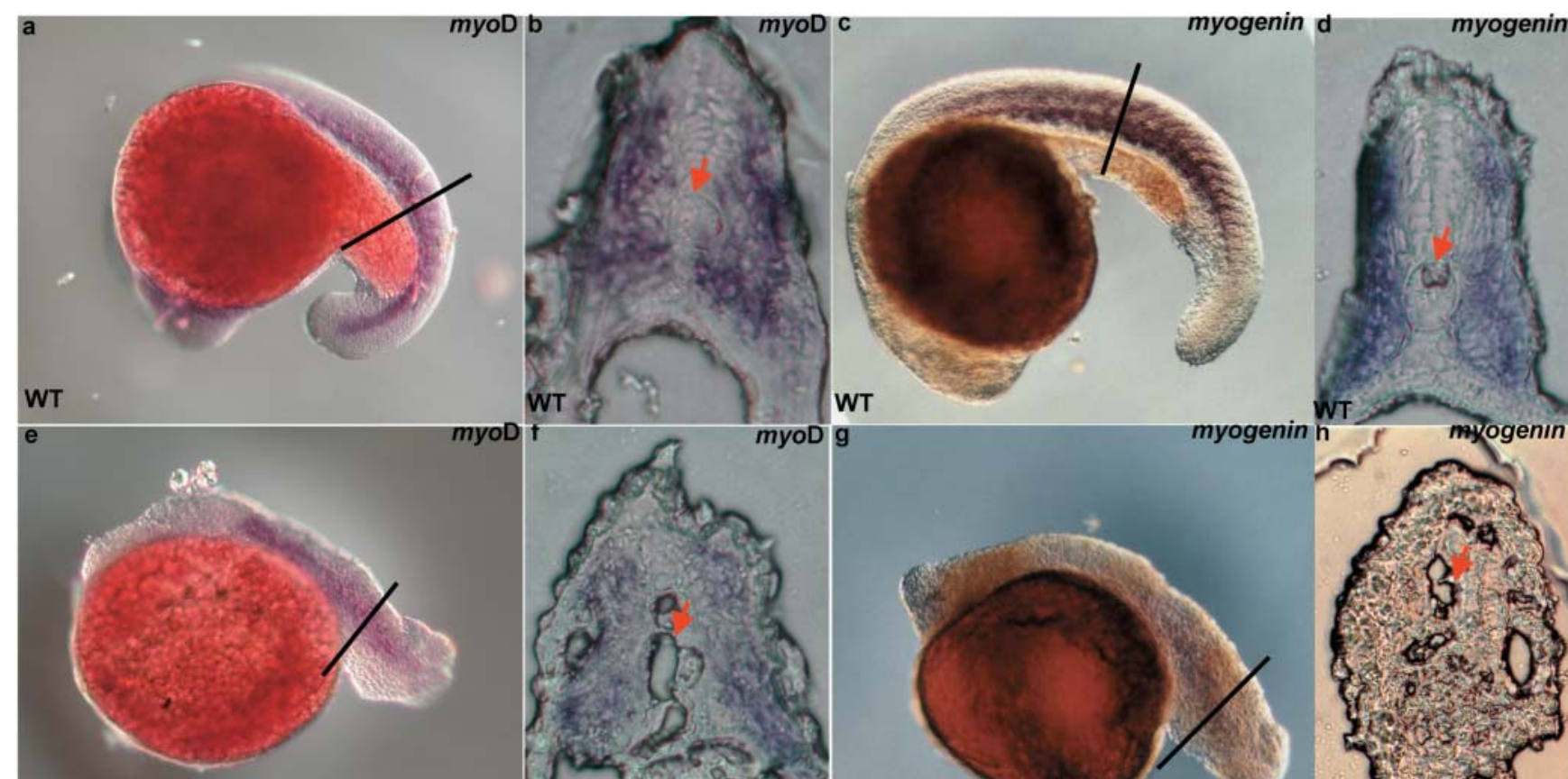

Morphant
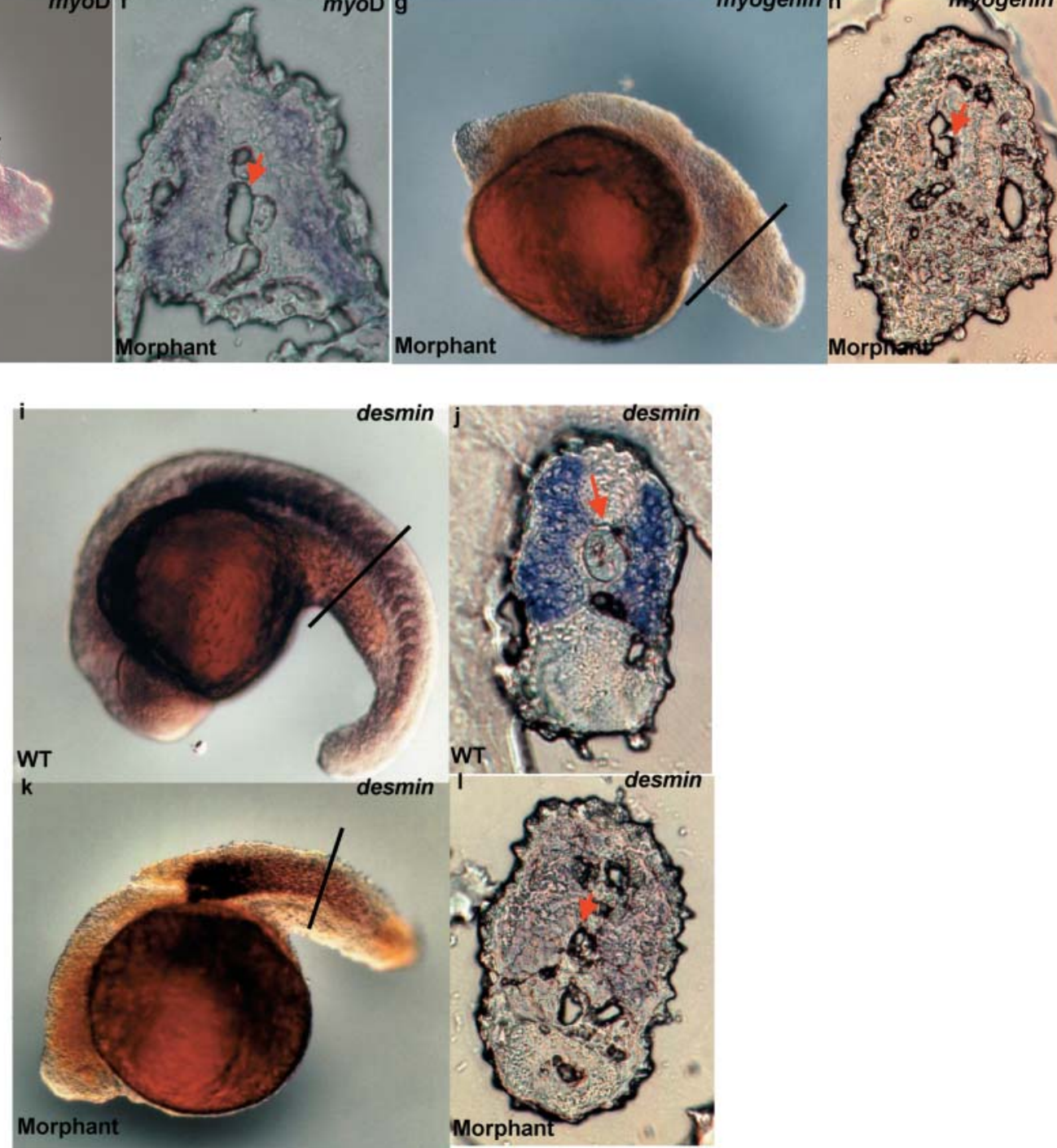

Fig. 3 Expression patterns of myoD, myogenin, and desmin transcripts in wild-type embryos and ZMF-morphants. Whole-mount in situ hybridization (a, c, e, $\mathbf{g}, \mathbf{i}$ and $\mathbf{k})$ and cryosectioning $(\mathbf{b}, \mathbf{d}, \mathbf{f}$, $\mathbf{h}, \mathbf{j}$ and $\mathbf{l}$ ) were performed using riboprobes as indicated. Lines in embryos indicate where cryosections were cut. Arrows indicate the position of notochord. sacs (Fig. 2d). At the end of the epibolic stage ( $\sim 9 \mathrm{hpf}$ ), myf5-MO-injected embryos developed bubble-like tail bud vesicles (Fig. 2e), which eventually formed abnormal tail buds that failed to attach to the yolk at $11.5 \mathrm{hpf}$ (Fig. 2f). Some embryos injected with higher dosages of
myf5-MO displayed abnormal somites at the middle segmental stage (18-24 hpf). Those abnormalities included morphologically indistinct somite boundaries, lack of uniformly sized cell blocks, unclear tail buds, and unclear horizontal myosepta (Figs. 2h and 2i). 


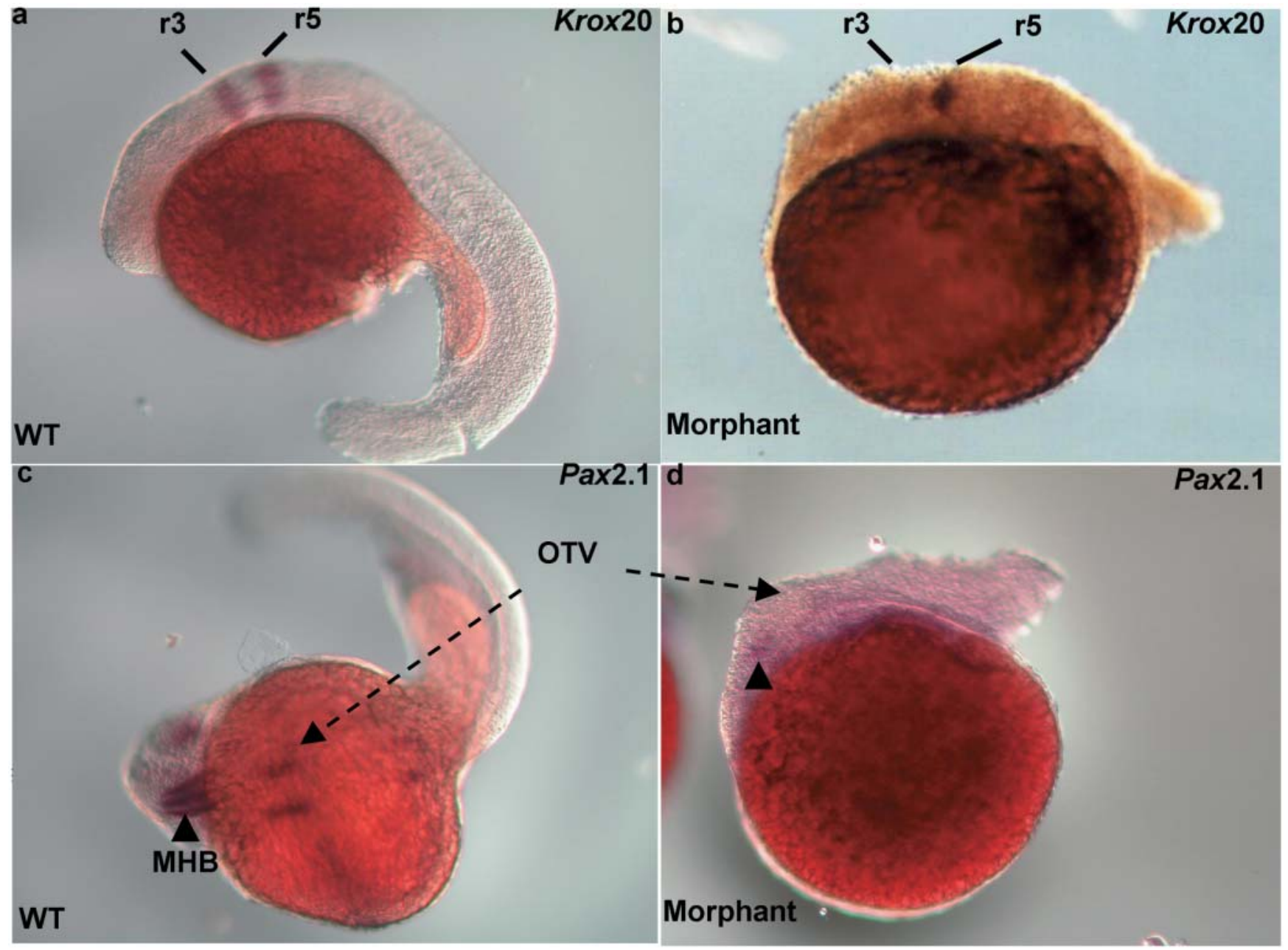

Fig. 4 Detection of brain markers, krox20 and pax2.1, in wild-type and MO-treated embryos. Krox20 (a, b) and pax2.1 (c, d) gene transcripts were detected in wild-type embryos $(\mathbf{a}, \mathbf{c})$ and ZMFmorphants (b, d, e). In the ZMF-morphants, krox20 transcripts were detected at r5 (b, arrow) but not r3. In the mild-defect ZMFmorphants, pax 2.1 transcripts were detected at the optic vesicle (d, dotted-arrows) and MHB (arrowhead). MHB: midbrain-hindbrain boundary; OTV: optic vesicle.
Abnormalities were categorized as mild or severe following morphological observations of myf5-MO-injected embryos at the end of the segmental stage ( $24 \mathrm{hpf})$. Mild defects mostly consisted of abnormal tail bud somites (Fig. 2i), with a few scorpion-like tails also noted. Severe defects included the absence of eyes and abnormal heads (diminished telencephalons and mesencephalons) in addition to the mild defects just described (Fig. 2h).

\section{Dose-dependent Myf5-morphant abnormalities}

Our results show that the frequency of phenotype abnormalities was myf5-MO dose-dependent (Table 1). At 1 ng, $9.3 \%$ (1.7\% mild, $7.6 \%$ severe) of the surviving embryos displayed defects; at $2.5 \mathrm{ng}$, the percentage increased to $14.6 \%$ (3.1\% mild, $11.5 \%$ severe), and at 4.5 ng, the rate jumped to $54.5 \%$ (15.6\% mild, $38.9 \%$ se- vere). In addition, a sharp decrease in survival rate (from approximately $60 \%$ to $25 \%$ ) was noted when embryos were treated with 9 ng myf5-MO: $56.4 \%(31 / 55)$ of the surviving embryos showed arrested growth during the epibolic stage (data not shown).

Similar efficacies for two Myf5-MO types

We injected the morpholino ZMF-OTHER into embryos to gather further proof that the defective morphant phenotype was the result of the endogenous myf5 knockdown. Abnormality rates resulting from $4.5 \mathrm{ng}$ injections of ZMF-OTHER (14.3\% mild and $32.3 \%$ severe) were similar to those caused by $4.5 \mathrm{ng}$ injections of ZMF-MO (15.6\% mild and $38.9 \%$ severe). The data suggest that the mild and severe defects were both the result of myf-5 knockdown phenotypes. 
Co-injection of capped zebrafish $m y f-5$ mRNA and ZMF-MO

We found that incidences of severe and mild defects were reduced when embryos were co-injected with various dosages of capped myf-5 RNA and $4.5 \mathrm{ng}$ of ZMF-MO. In the low-dosage-injection group $(0.23 \mathrm{ng} / \mathrm{embryo})$, the abnormality rate decreased from $49.6 \%(15.8 \%$ mild and $33.8 \%$ severe) to $41.8 \%$ (12.7\% mild and $29.1 \%$ severe); in the high-dosage-injection group (4.5 ng/embryo), the abnormality rate decreased significantly to 5.5 $\%$ (5.5\% mild and $0 \%$ severe) (Table 2$)$. However, severe and mild defects increased slightly in control group embryos co-injected with $4.5 \mathrm{ng}$ of capped GFP RNA and ZMF-MO (52.1\% total, $16.1 \%$ mild and $35 \%$ severe) (Table 2). According to the data, the effect of ZMF-MO on knockdown myf-5 was both distinct and consistent.

\section{Zebrafish Myf-5 and somitogenesis}

To identify which muscle-specific genes were down-regulated in the 24-hpf ZMF morphants (resulting in somitepatterning defects), we performed whole-mount in situ hybridization with zebrafish myoD, myogenin, and desmin riboprobes. Our results show that myoD transcripts were strongly detectable in the somites and adaxial cells of wild-type embryos (Fig. 3a). Myogenin expression patterns were similar to those for myoD (Fig. 3c). In ZMF-morphants, myogenin transcripts were substantially down-regulated in the entire somite block (Fig. $3 \mathrm{~g}$ ), but myoD transcripts were not (Fig. 3e).

Our inspections of somite block cross-sections showed that myogenin transcripts appeared in the entire somite block, including slow- and fast-muscle pioneers in normal embryos (Fig. 3d), but they were just barely detectable in morphants (Fig. 3h). On the other hand, desmin transcripts were strongly detectable in whole somite blocks (anterior to posterior) as well as in slow- and fastmuscle pioneers, including adaxial cells (Figs. $3 \mathrm{j}$ and 31 ). In the oldest 24-hpf ZMF-morphant somites, desmin transcripts were clearly detectable, although with vague contours (Fig. 3k). The only signs of desmin inhibition were noted in newly forming somites (Fig. 3k). Note that all sections of myf5-morphants displayed a shrinkage notochord (Figs. 3f, 3h and 3i), indicating that Myf5 may be involved in notochord formation.

\section{Zebrafish krox20 and pax2.1 transcripts}

Our results show that ZMF-MO treatment resulted in severe brain defects in ZMF-MO morphants. We used the same procedure just described with forebrain (pax2.1) and hindbrain (krox20) riboprobes to identify which portions of the brain in zebrafish were affected by ZMF-MO. In normal embryos, pax2.1 transcripts were detected in the forebrain, midbrain-hindbrain boundary (MHB), and optic stalk (Fig. 4c); krox20 transcripts were detected in rhombomeres 3 and 5 (r3 and r5) (Fig. 4a). The krox20 transcripts were expressed normally at the $r 5$ primordium, but down-regulated at $r 3$ (Fig. 4b). In contrast, pax 2.1 transcripts were strongly detected in the optic primordium and MHB (Fig. 4c), but were substantially down-regulated in the forebrains of mildly defective ZMF-morphants (Fig. 4d).

\section{Discussion}

RNA-interference (RNAi) has been described as being very strong in Caenorhabditis elegans (Fire et al., 1998) and Drosophila (Misquitta and Paterson, 1999); Zhao et al. (2001) reported an unacceptably high level of RNAi in zebrafish. The use of a morpholino is currently considered the best antisense approach for in vivo studies of knockdown gene function in zebrafish (Nasevicius and Ekker, 2000; Ekker and Larson, 2001) for known (Dutton et al., 2001) as well as novel genes (Scholpp and Brand, 2001).

\section{Epiblast convergence and extension}

Data from our whole-mount in situ hybridization show that endogenous zebrafish myf-5 transcripts were first detected at $70 \%$ epiboly, reached maximum expression at 16 hpf, and down-regulated at the end of the segmentation stage. ZMF-morphant defects were also first noticed at 70 $\%$ epiboly (Fig. 2d); a RT-PCR analysis revealed that endogenous zebrafish $m y f-5$ transcripts were weakly detectable at $50 \%$ epiboly (data not shown). Chen et al. (unpublished results) found that injection with a DNA construct containing zebrafish $m y f-5$ upstream -9977 to -1 fused with a GFP reporter gene resulted in green signals becoming detectable in epiblasts at $50 \%$ epiboly; by this point, epiblasts are undergoing convergence and extension, and cell lineages are becoming increasingly specific. Kiefer and Hauschka (2001) found that chicken myf-5 was expressed in epiblasts at $50 \%$ epiboly and were expressed in some non-muscle mesodermic cells following wholemount in situ hybridization. In the present study, half of the surviving embryos in the 9 ng-injected myf5-MO group showed arrested growth during the epibolic stage. In the case of total myf-5 knockdown, embryos were unable to complete the epibolic stage and commence with segmentation. We therefore suggest that zebrafish Myf-5 has multiple functions, including epiblast migration and segmentation.

\section{Myf-5 knockdown phenotypes}

At $24 \mathrm{hpf}$, ZMF morphants displayed mild and severe defects. Both ZMF-MO (nt 28 to 52 of the antisense 
strand) and ZMF-OTHER (nt 3 to 27 of the antisense strand) were capable of causing such defects in 24-hpf morphants. No significant differences were noted in survival rates between embryos treated with either ZMFMO (53.9\%) or ZMF-OTHER (57.1\%), but a slightly larger difference was noted in defective rates resulting from ZMF-MO treatment (54.5\%) compared to ZMFOTHER treatment $(46.6 \%)$; this may be due to different blocking translation efficiencies between the two. Defect reduction attributed to the co-injection of ZMF-MO and capped myf-5 RNA was dose-dependent (Table 2). Following injections of capped myf-5 RNA at dosages as high as $4.5 \mathrm{ng} / \mathrm{embryo}$, morphant survival was measured at $43.1 \%$ with a defect rate of only $5.5 \%$. However, injections of capped GFP RNA were incapable of reducing defective embryo rates (Table 2). These observations indicate that the mild and severe defects noted in this study were both distinct and consistent.

Comparing zebrafish ZMF-morphant and mice myf-5 knockout phenotypes

Zebrafish embryos treated with myf-5 morpholino showed developmental defects, including epiblast migration retardment, abnormal somite patterning, brain deformation, and lethal effect of embryos. Severe rib defects and embryonic death were also noted in myf-5 knockout mice embryos, but defects in epiblast migration, somite patterning, and brain formation have not been reported. The greater number of abnormalities found in zebrafish treated with $m y f-5$ morpholino may be due to a) a more concentrated effort to identify zebrafish morphants, and/or b) Myf-5 performs different biological functions in fish and mammalian systems.

\section{Biological functions of Myf-5 during somitogenesis}

In this study, zebrafish morphants showed abnormal muscle and defective somite patterning, suggesting that Myf-5 is essential to muscle development. To identify which muscle-specific factors are regulated by Myf-5 during somitogenesis, we searched for myo $\mathrm{D}$, myogenin, and desmin expression patterns in wild-type embryos and ZMF-morphants. Myf-5, MyoD, and Myogenin are all classified as basic helix-loop-helix transcription factors, with MyoD being involved in myocyte determination and Myogenin being involved in myotube formation (Rudnicki and Jaenisch, 1995). Desmin is a musclespecific intermediate filament protein that is regulated by Myf-5, MyoD, and Myogenin in mice ( $\mathrm{Li}$ and Capetanaki, 1993; Rudnicki et al., 1993; Li et al., 1994). We detected desmin transcripts in zebrafish in both the superficial muscle cells and the deeper parts of myotomes (Figs. 3i and 3j). These were co-localized with $m y f-5$, myo $\mathrm{D}$, and myogenin, suggesting that desmin is also regulated by MRFs. According to Braun et al. (1992) and Rudnicki et al. (1992), Myf-5 and MyoD compensate for each other in mice. Both teams of researchers also found normal myogenin and desmin transcription levels in myoD or myf-5 knockout mice. Hollenberg et al. (1993) demonstrated that myogenin is a direct transcriptional target of MyoD. Surprisingly, our results show that myoD transcripts were not affected in $m y f-5$ knockdown zebrafish, but that myogenin and desmin transcripts were down-regulated in all somites and newly forming somites, respectively. Recently, Lindon et al. (2001) proposed that Myf-5 is a potent inducer of myogenin at high cell densities; there is also evidence that Myf-5 is fully capable of activating myogenin. We therefore suggest that myogenin is a transcriptional target found downstream of both $m y f-5$ and myoD.

\section{ZMF-morphants display brain abnormalities}

Another possible explanation for brain abnormalities resulting from myf-5 knockdown zebrafish is reduced skeletal muscle. During nervous system development, motor neurons are believed to compete for specific skeletal muscle sites, with their long-term survival dependent upon receiving trophic support from the targeted muscle (Oppenheim, 1996). In addition, Kablar and Rudnicki (1999) report that motor neurons in mice normally appear in the spinal cord, and that all somatic motor neurons in mutant mice are eliminated by apoptosis in $m y f 5^{-1-}: m y o \mathrm{D}^{-1-}$ double knockout mice. Sporle et al. (1996) described brain defects and strongly altered $m y f-$ 5 expression patterns in open brain (opb) mutant mice. Combined, this evidence suggests that nervous development is intimately coupled with skeletal myogenesis. Clearly, myf-5 mRNAs exist in the central nervous system (CNS), but their biological functions during neuron or brain development require further study.

Finally, we found that reduced krox20 and pax2.1 expression domains in the anterior hindbrain region resulted in MHB and $\mathrm{r} 3$ hypoplasia. We therefore suggest that zebrafish Myf-5 may not be essential for hindbrain segmentation and specification, but may be essential for krox 20 activation in the anterior hindbrain region.

\section{Myf-5 may be involved in neurogenesis}

Most studies on Myf-5 focus on myogenesis. However, Tajbakhsh and Buckingham (1995) detected myf-5 transcripts in mice brains, and therefore suggested that myf5 might play an important role in brain development. Furthermore, Daubas et al. (2000), Hadchouel et al. (2000), and Carvajal et al. (2001) detected myf-5 mRNA in the CNS of mice, and therefore suggested that CNSspecific cis-elements may occur in the upstream $-8.8 \mathrm{~kb}$. These reports clearly show the presence of myf -5 tran- 
scripts in neurons, but their biological roles during neurogenesis remain unclear.

In this study, we observed that brain development was impeded in myf5-MO-treated embryos. According to Chen et al. (unpublished results), a) the zebrafish -2937 to $-290(-2937 /-290)$ myf-5 upstream regulatory sequence contains notochord-specific elements and b) in germ-line transmitted zebrafish, an myf-5 -6212/-1 segment fused with EGFP is capable of directing GFP expression in the spinal cord. Based on these observations, we propose the possible presence of a neuronspecific regulatory element within the zebrafish myf-5 gene. Zeller and Granato (1999) demonstrated that a distinct population of myotomal cells plays a pivotal role in the early migration of zebrafish motor axons. They also identified the diwanka gene as a somite-derived cue that is required for establishing an axonal path from the spinal cord to the somites. Their evidence provides insight into how neuronal and myotomal precursor cells are linked, and raise the possibility that the zebrafish $m y f-5$ gene may follow the same pathway.

\section{Comparing ZMF-morphants with known mutants}

Two types of somite-defective zebrafish mutants have been described and used for comparisons with myf5-

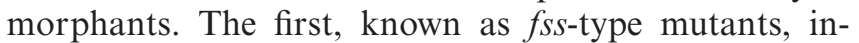
clude defects associated with the segmentation and epithelialization of the somatic mesoderm: fused somites (fss), beamters (bea), deadly sevens (des) and after eights (aei) (van Eeden et al., 1996). In each of these, the segmental expression of MyoD in unsegmented regions is lost, but it is expressed throughout the somatic mesoderm (van Eeden et al., 1996). In the present study, the myoD transcripts were normally expressed in myf5-morphants (Fig. 3), therefore we can rule out the possibility that myf5-morphants are $f_{S s}$-type mutants. Because they all result in U-shaped somites, the second group is known as you-type mutants; they include you (you), youtoo (yot), slow-muscle-omitted (smu), and sonic-you (syu) (van Eeden et al., 1996; Schauerte et al., 1998; Barresi et al., 2000; Varga et al., 2001). While we noticed that the somite boundaries of myf5-morphants were missing, they could not be considered U-shaped (Fig. 2).

In other words, the myf5-morphants in our study displayed somite patterning defects that are not phenotypically similar to either $f s s$ - or you-type mutants. This makes them similar to myf5-morphants with such brain mutations as no isthmus (noi) and white tail (wit); the former lacks MHB, while the latter has some character-

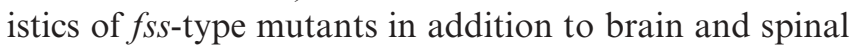
cord deficiencies (Brand et al., 1996; Jiang et al., 1996). A search of current databases failed to identify mutants that are phenotypically similar to the myf5-morphants observed in this study. We found that myf-5 in knockdown zebrafish is lethal to embryos, in the same way that it is lethal to the embryos of knockout mice (Braun et al., 1992). These results indicate the importance of $m y f-5$ to early embryonic development. They may also explain why such an upstream control gene as myf-5 does not present phenotypes that overlap with other genes that are involved in these development pathways.

Our conclusion is that even though Myf-5 is best known as a muscle regulatory factor in somites, zebrafish Myf-5 is involved in the convergence and extension of shield epiblasts, tail buds, and brain formation during early embryogenesis.

Acknowledgements We are grateful to Dr. Wen-Chang Chang, Institute of Biochemical Science, for providing plasmids containing cDNAs of pax2.1 and krox20. We are also grateful to Prof. RueyPing Lin, Department of Zoology, for helping us with the cryosection experiments. This research was supported by the National Science Council, Republic of China (grant no. NSC 90-2313B002-260).

\section{References}

Barresi, M.J.F., Stickney, H.L. and Devoto, S.H. (2000) The zebrafish slow-muscle-omitted gene product is required for Hedgehog signal transduction and the development of the slow muscle identity. Development 127:2189-2199.

Brand, M., Heisenberg, C.P., Jiang, Y.J., Beuchle, D., Lun, K., Furutani-Seiki, M., Granato, M., Haffter, P., Hammerschmidt, M., Kane, D., Kelsh, R., Mullins, M., Odenthal, J., van Eeden, F.J.M. and Nusslein-Volhard, C. (1996) Mutations in zebrafish genes affecting the formation of the boundary between midbrain and hindbrain. Development 123:179-190.

Braun, T., Rudnicki, M.A., Arnold, H.H. and Jaenisch, R. (1992) Targeted inactivation of the muscle regulatory gene Myf-5 results in abnormal rib development and perinatal death. Cell 71:369382 .

Buonanno, A., Apone, L., Morasso, M.I., Beers, R., Brenner, H.R. and Eftimie, R. (1992) The MyoD family of myogenic factors is regulated by electrical activity: isolation and characterization of a mouse Myf-5 cDNA. Nucleic Acids Res 20:539-544.

Carvajal, J.J., Cox, D., Summerbell, D. and Rigby, P.W.J. (2001) A BAC transgenic analysis of the Mrf4/ Myf5locus reveals interdigitated elements that control activation and maintenance of gene expression during muscle development. Development 128:1857-1868.

Chen, Y.H., Lee, W.C., Cheng, C.H. and Tsai, H.J. (2000) Muscle regulatory factor gene: zebrafish (Danio rerio) myogenin cDNA. Comp Biochem Physiol 127B:97-103.

Chen, Y.H., Lee, W.C., Liu, C.F. and Tsai, H.J. (2001) Molecular structure, dynamic expression and promoter analysis of zebrafish (Danio rerio) myf-5 gene. Genesis 29:22-35.

Chen, Y.H., Liang, C.T. and Tsai, H.J. (2002) Expression, purification and DNA-binding activity of tilapia muscle-specific transcription factor MyoD, produced in Escherichia coli. Comp Biochem Physiol 131B:795-805.

Coutelle, O., Blagden, C.S., Hampson, R., Halai, C., Rigby, P.W.J. and Hughes, S.M. (2001) Hedgehog signaling is required for maintenance of myf 5 and myoD expression and timely terminal differentiation in zebrafish adaxial myogenesis. Dev Biol 236:136-150.

Daubas, P., Tajbakhsh, S., Hadchouel, J., Primig, M. and Buckingham, M. (2000) Myf5 is a novel early axonal marker in the mouse brain and is subjected to post-transcriptional regulation in neurons. Development 127:319-331. 
Devoto, S.H., Melancon, E., Eisen, J.S. and Westerfield, M. (1996) Identification of separate slow and fast muscle precursor cells in vivo, prior to somite formation. Development 122:3371-3380.

Dutton, K., Dutton, J.R., Pauliny, A. and Kelsh, R.N. (2001) A morpholino phenocopy of the colourless mutant. Genesis 30:188-189.

Ekker, S.C. and Larson, J.D. (2001) Morphant technology in model developmental system. Genesis 30:89-93.

Fire, A., Xu, S., Montgomery, M.K., Kostas, S.A., Driver, S.E. and Mello, C.C. (1998) Potent and specific genetic interference by double-stranded RNA in Caenorhabditis elegans. Nature 391:806-811.

Fisher, S., Amacher, S.L. and Halpern, M.E. (1997) Loss of cerebrum function ventralizes the zebrafish embryo. Development 124:1301-1311.

Hadchouel, J., Tajbakhsh, S., Primig, M., Chang, T.H.T., Daubas, P., Rocancourt, D. and Buckingham, M. (2000) Modular longrange regulation of Myf5 reveals unexpected heterogeneity between skeletal muscles in the mouse embryo. Development 127:4455-4467.

Hammerschmidt, M., Pelegri, F., Mullins, M.C., Kane, D.A., van Eeden, F.J., Granato, M., Brand, M., Furutani-Seiki, M., Haffter, P., Heisenberg, C.P., Jiang, Y.J., Kelsh, R.N., Odenthal, J., Warga, R.M. and Nusslein-Volhard, C. (1996) dino and mercedes, two genes regulating dorsal development in the zebrafish embryo. Development 123:95-102.

Hollenberg, S.M., Cheng, P.F. and Weintraub, H. (1993) Use of a conditional MyoD transcription factor in studies of MyoD transactivation and muscle determination. Proc Natl Acad Sci USA 90:8028-8032.

Hopwood, N.D., Pluck, A. and Gurdon, J.B. (1991) Xenopus Myf5 marks early muscle cells and can activate muscle genes ectopically in early embryos. Development 111:551-560.

Jiang, Y.J., Brand, M., Heisenberg, C.P., Beuchle, D., FurutaniSeiki, M., Kelsh, R.N., Warga, R.M., Granato, M., Haffter, P., Hammerschmidt, M., Kane, D.A., Mullins, M.C., Odenthal, J., van Eeden, F.J.M. and Nusslein-Volhard, C. (1996) Mutations affecting neurogenesis and brain morphology in the zebrafish, Danio rerio. Development 123:205-216.

Kablar, B. and Rudnicki, M.A. (1999) Development in the absence of skeletal muscle results in the sequential ablation of motor neurons from the spinal cord to the brain. Dev Biol 208:93-109.

Kiefer, J.C. and Hauschka, S.D. (2001) Myf-5 is transiently expressed in nonmuscle mesoderm and exhibits dynamic regional changes within the presegmented mesoderm and somites I-IV. Dev Biol 232:77-90.

Kimmel, C.B., Ballard, W.W., Kimmel, S.R., Ullmann, B. and Schilling, T.F. (1995) Stages of embryonic development of the zebrafish. Dev Dyn 203:253-310.

Krause, M., Harrison, S.W., Xu, S.Q., Chen, L. and Fire, A. (1994) Elements regulating cell- and stage-specific expression of the $C$. elegans MyoD family homolog hlh-1. Dev Biol 166:133-148.

Li, H. and Capetanaki, Y. (1993) Regulation of the mouse desmin gene: transactivated by MyoD, myogenin, MRF4 and Myf5. Nucleic Acids Res 21:335-343.

Li, H, Choudhary, S.K., Milner, D.J., Munir, M.I., Kuisk, I.R. and Capetanaki, Y. (1994) Inhibition of desmin expression blocks myoblast fusion and interferes with the myogenic regulators MyoD and myogenin. J Cell Biol 124:827-841.

Lindon, C., Albagli, O., Pinset, C. and Montarras, D. (2001) Cell density-dependent induction of endogenous myogenin (myf-4) gene expression by Myf5. Dev Biol 240:574-584

Loh, S.H., Chan, W.T., Gong, Z., Lim, T.M. and Chua, K.L. (2000) Characterization of a zebrafish (Danio rerio) desmin cDNA: an early molecular marker of myogenesis. Differentiation 65:247254.

Michelson, A.M., Abmayr, S.M., Bate, M., Arias, A.M. and Maniatis, T. (1990) Expression of a MyoD family member prefigures muscle pattern in Drosophila embryos. Genes Dev 4:2086-2097.
Misquitta, L. and Paterson, B.M. (1999) Targeted disruption of gene function in Drosophila by interference (RNA-i): a role for nautilus in embryonic somatic muscle formation. Proc Natl Acad Sci USA 96:1451-1456.

Nasevicius, A. and Ekker, S.C. (2000) Effective targeted gene "knockdown" in zebrafish. Nature Genet 26:216-220.

Neyt, C., Jagla, K., Thisse, C., Thisse, B., Haines, L. and Currie, P.D. (2000) Evolutionary origins of vertebrate appendicular muscle. Nature 408:82-84.

Oppenheim, R.W. (1996) Neurotrophic survival molecules for motoneurons: an embarrassment of riches. Neuron 17:195-197.

Oxtoby, E. and Jowett, T. (1993) Cloning of the zebrafish krox-20 gene $(k r x-20)$ and its expression during hindbrain development. Nucleic Acids Res 12:1087-1095.

Pfeffer, P.L., Gerster, T., Lun, K., Brand, M. and Busslinger, M. (1998) Characterization of three novel members of the zebrafish Pax2/5/8 family: dependency of Pax 5 and Pax 8 expression on the Pax2.1 (noi) function. Development 125:3063-3074.

Rudnicki, M.A., Braun, T., Hinuma, S. and Jaenisch, R. (1992) Inactivation of MyoD in mice leads to up-regulation of the myogenic HLH gene Myf-5 and results in apparently normal muscle development. Cell 71:383-390.

Rudnicki, M.A. and Jaenisch, R. (1995) The MyoD family of transcription factors and skeletal myogenesis. Bioessays 17:203-209.

Rudnicki, M.A., Schnegelsberg, P.N., Stead, R.H., Braun, T., Arnold, H.H. and Jaenisch, R. (1993) MyoD or Myf-5 is required for the formation of skeletal muscle. Cell 75:1351-1359.

Saitoh, O., Fujisawa-Sehara, A., Nabeshima, Y. and Periasamy, M. (1993) Expression of myogenic factors in denervated chicken breast muscle: isolation of the chicken Myf5 gene. Nucleic Acids Res 21:2503-2509.

Schauerte, H.E., van Eeden, F.J.M., Fricke, C., Odenthal, J., Strahle, U. and Haffter, P. (1998) Sonic Hedgehog is not required for floor plate induction in the zebrafish. Development 125:29832993.

Scholpp, S. and Brand, M. (2001) Morpholino-induced knockdown of zebrafish engrailed genes eng2 and eng3 reveals redundant and unique functions in midbrain-hindbrain boundary development. Genesis 30:129-133.

Sporle, R., Gunther, T., Struwe, M. and Schughart, K. (1996) Severe defects in the formation of epaxial musculature in open brain $(o p b)$ mutant mouse embryos. Development 122:79-86.

Tajbakhsh, S. and Buckingham, M.E. (1995) Lineage restriction of the myogenic conversion factor myf-5 in the brain. Development 121:4077-4083.

van Eeden, F.J., Granato, M., Schach, U., Brand, M., Furutani-Seiki, M., Haffter, P., Hammerschmidt, M., Heisenberg, C.P., Jiang, Y.J., Kane, D.A., Kelsh, R.N., Mullins, M.C., Odenthal, J., Warga, R.M., Allende, M.L., Weinberg, E.S. and Nüsslein-Volhard, C. (1996) Mutations affecting somite formation and patterning in the zebrafish, Danio rerio. Development 123:153-64.

Varga, Z.M., Amores, A., Lewis, K.E., Yan, Y.L., Postlethwait, J.H., Eisen, J.S. and Westerfield, M. (2001) Zebrafish smoothened functions in ventral neural tube specification and axon tract formation. Development 128:3497-3509.

Weinberg, E.S., Allende, M.L., Kelly, C.S., Abdelhamid, A., Murakami, T., Andermann, P., Doerre, O.G., Gruwald, D.J. and Riggleman, B. (1996) Developmental regulation of zebrafish MyoD in wild-type, no tail and spadetail embryos. Development 122:271-280.

Xu, Y., He, J., Wang, X., Lim, T.M. and Gong, Z. (2000) Asynchronous activation of 10 muscle-specific protein (MSP) genes during zebrafish somitogenesis. Dev Dyn 219:201-215.

Zeller, J. and Granato, M. (1999) The zebrafish diwanka gene controls an early step of motor growth cone migration. Development 126:3461-3472.

Zhao, Z., Cao, Y., Li, M. and Meng, A. (2001) Double-stranded RNA injection produces nonspecific defects in zebrafish. Dev Biol 229:215-223. 